\title{
ANALISI PENURUNAN FONDASI TIANG RAKIT TERHADAP PENGARUH LIKUIFAKSI DI SULAWESI
}

\author{
Wesley Kohar ${ }^{1}$ dan Aniek Prihatiningih ${ }^{2}$ \\ ${ }^{1}$ Program Studi Sarjana Teknik Sipil, Universitas Tarumanagara, Jl. Letjen S. Parman No.1 Jakarta \\ Wesley.325150153@stu.untar.ac.id \\ ${ }^{2}$ Program Studi Sarjana Teknik Sipil, Universitas Tarumanagara, Jl. Letjen S. Parman No.1 Jakarta \\ aniekp@ft.untar.ac.id
}

\begin{abstract}
Liquefaction is one of the most dangerous effect of earthquake. When earthquake happens, the soil characteristic will change from solid to liquid state because of the dynamic cyclic load. Buildings that sits on such soil will totally fail because of the soil loss of bearing capacity. So, detailed analysis and evaluation of the potential of liquefaction when earthquake occurs is needed, such as CSR and CRR, Chinese Criteria, Tsuchida, Bray \& Sancio and Seed et al. The result of the analyses will be compared to each method to other. The result of the analysis will show whether liquefaction happen or not in every layer of the analysed soil. Steps that that are usually made by the geotechnical engineer expert is that the soil need to be improved beforehand. But in this study. Piled-raft foundation which is combination of piled and raft foundation is used for settlement analysis. The result of the analysis will show the settlement of the foundation before and after its affected by liquefaction.
\end{abstract}

Keywords: earthquake; liquefaction; liquefaction potensial; piled-raft foundation; settlement

\begin{abstract}
ABSTRAK
Likuifaksi merupakan salah satu peristiwa yang sangat bahaya yang ditimbulkan oleh bencana bumi. pada saat gempa bumi terjadi, sifat tanah akan berubah dari solid menjadi liquid akibat beban siklik yang terjadi. Bangunan yang menempati tanah yang mengalami likuifaksi akan langsung gagal total karena tanah mengalami kehilangan daya dukung. Untuk itu, diperlukan metode-metode yang rinci untuk menganalisis dan mengevaluasi potensi terjadinya likuifaksi saat terjadi gempa, yaitu analisis potensi likuifaksi yang dapat berupa analisis CSR dan CRR, Chinese Criteria, Tsuchida, Bray \& Sancio dan Seed et al. Hasil analisis potensi likuifkasi tersebut akan dibandingkan satu metode dengan yang lainnya. Hasil analisis menunjukan potensi terjadinya likuifaksi pada tiap lapisan tanah yang akan ditampilkan dalam bentuk grafik maupun tabel. Fondasi tiang rakit yang merupakan gabungan antara fondasi tiang dan rakit digunakan untuk analisis penurunan fondasi pada skripsi ini. Hasil analisis akan menunjukan penurunan fondasi sebelum dan setelah likuifaksi terjadi yang akan ditampilkan dalam bentuk tabel.
\end{abstract}

Kata kunci: gempa bumi; likuifaksi; potensi likuifaksi; fondasi tiang rakit; penurunan

\section{PENDAHULUAN}

Gempa bumi dapat mengakibatkan struktur bangunan bagian atas maupun bawah mengalami kegagalan. Karena getaran yang disebabkan oleh gempa bumi dapat membuat tanah seolah-olah menjadi air yang artinya tanah mengalami kehilangan daya dukung. Peristiwa ini disebut peristiwa likuifaksi. Likuifaksi adalah proses perubahan kondisi tanah pasir yang jenuh air menjadi cair akibat meningkatnya tekanan air pori yang besarnya menjadi sama dengan tekanan total akibat terjadinya beban dinamik, sehingga tegangan efektif tanah menjadi nol. Likuifaksi dapat menimbulkan berbagai dampak seperti, Sand Boils, Flow Failure, Lateral Spread, Ground Oscillation, Loss of Bearing Capacity, Ground Settlement. Tujuan penelitian ini adalah mengetahui potensi likuifaksi dan penambahan penurunan berdasarkan data tanah yang ada dengan menggunakan fondasi tiang rakit sebagai fondasi yang akan dianalisis. Harapanya penelitian ini dapat bermanfaat untuk para ahli geoteknik untuk dijadikan sebagai patokan dalam perencanaan karena mampu memberikan pertimbangan efek likuifaksi pada daerah itu, serta diharapkan dapat menjadi inspirasi dan sebagai ilmu pengetahuan yang dapat digunakan sebagai bahan referensi 
bagi penelitian sejenis yang akan dilakukan ataupun diaplikasikan sebagai perencanaan struktur bawah di daerah yang memiliki kondisi yang sama.

\section{Fondasi tiang rakit}

Fondasi tiang rakit digunakan ketika fondasi rakit melewati batas-batas izin penurunan dan tegangan. Selain itu, fondasi tiang rakit dapat dipakai untuk tanah yang memiliki daya dukung yang rendah dan harus memikul beban yang besar. Penggunaan fondasi tiang bersama dengan fondasi rakit dapat mengurangi penurunan (Poulos, 2001).

\section{Daya dukung fondasi rakit}

Perhitungan daya dukung fondasi rakit menggunakan rumus (Terzaghi, 1943) dengan asumsi keruntuhan geser menyeluruh, sebagai berikut:

$$
q_{u l t}=c \times N_{c} \times S_{c}+q \times N_{q}+0.5 \times \gamma \times B \times N_{y} \times S_{\gamma}
$$

dengan $\mathrm{q}_{\mathrm{ult}}=$ Daya Dukung Metode Terzaghi, $\mathrm{c}=$ kohesi, $\mathrm{Nc}=$ faktor kapasitasd dukung, Sc $=$ faktor bentuk fondasi, $\mathrm{q}=$ tegangan effektif, $\mathrm{Nq}=$ factor kapasitas daya dukung, $\gamma=$ Berat Jenis Tanah, $\mathrm{B}=$ Lebar Alas Fondasi, $\mathrm{Ny}=$ factor kapasitas daya dukung, Sy = factor bentuk fondasi.

Tabel 1. Faktor bentuk fondasi

\begin{tabular}{cccc}
\hline for & Strip & Round & Square \\
\hline $\mathrm{S}_{\mathrm{c}}$ & 1.0 & 1.3 & 1.3 \\
$\mathrm{~S} \gamma$ & 1.0 & 0.6 & 0.8 \\
\hline
\end{tabular}

(Sumber: Bowles, 1996)

Tabel 2. Faktor kapasitas daya dukung fondasi

\begin{tabular}{ccccc}
\hline$\phi$ & $\mathrm{N}_{\mathrm{c}}$ & $\mathrm{N}_{\mathrm{q}}$ & $\mathrm{N}_{\gamma}$ & $\mathrm{K}_{\mathrm{py}}$ \\
\hline 0 & 5.7 & 1 & 0 & 10.8 \\
5 & 7.3 & 1.6 & 0.5 & 12.2 \\
10 & 9.6 & 2.7 & 1.2 & 14.7 \\
15 & 12.9 & 4.4 & 2.5 & 18.6 \\
20 & 17.7 & 7.4 & 5 & 25 \\
25 & 25.1 & 12.7 & 9.7 & 35 \\
30 & 37.2 & 22.5 & 19.7 & 52 \\
35 & 52.6 & 36.5 & 36 & 82 \\
40 & 57.8 & 41.4 & 42.4 & 141 \\
45 & 95.7 & 81.3 & 100.4 & 298 \\
50 & 172.3 & 173.3 & 294.5 & 800 \\
55 & 258.3 & 287.9 & 780.1 & \\
60 & 347.5 & 415.1 & 1153.2 & \\
\hline
\end{tabular}

(Sumber: Bowles, 1996)

Tabel 1 dan 2 digunakan untuk mencari koefisien yang akan digunakan dalam menganalisis daya dukung fondasi rakit.

\section{Daya dukung fondasi tiang}

Tipe tiang yang digunakan pada penelitian ini adalah tiang bor dan rumus yang digunakan dalam menganalisis daya dukung fondasi tiang tersebut adalah menggunakan metode Reese \& Wright (1977).

$$
Q_{u}=Q_{p}+Q_{s}+W_{p}
$$

dengan $\mathrm{Q}_{\mathrm{u}}=$ daya dukung ultimit tiang $\mathrm{Q}_{\mathrm{p}}=$ daya dukung ujung tiang, $\mathrm{Qs}=$ daya dukung selimut tiang, Wp = berat fondasi tiang.

\section{Daya dukung ujung tiang}

$$
\mathrm{Qp}=\frac{\mathrm{Axqp}}{\mathrm{FK}}
$$

dengan $\mathrm{A}=$ luas penampang tiang bor, $\mathrm{FK}$ = faktor keamanan, $\mathrm{qp}$ = tahanan ujung per satuan luasan Untuk tanah non-kohesif, tahanan ujung per satuan luas dapat diambil pada gambar 1 sesuai dengan usulan Reese. 


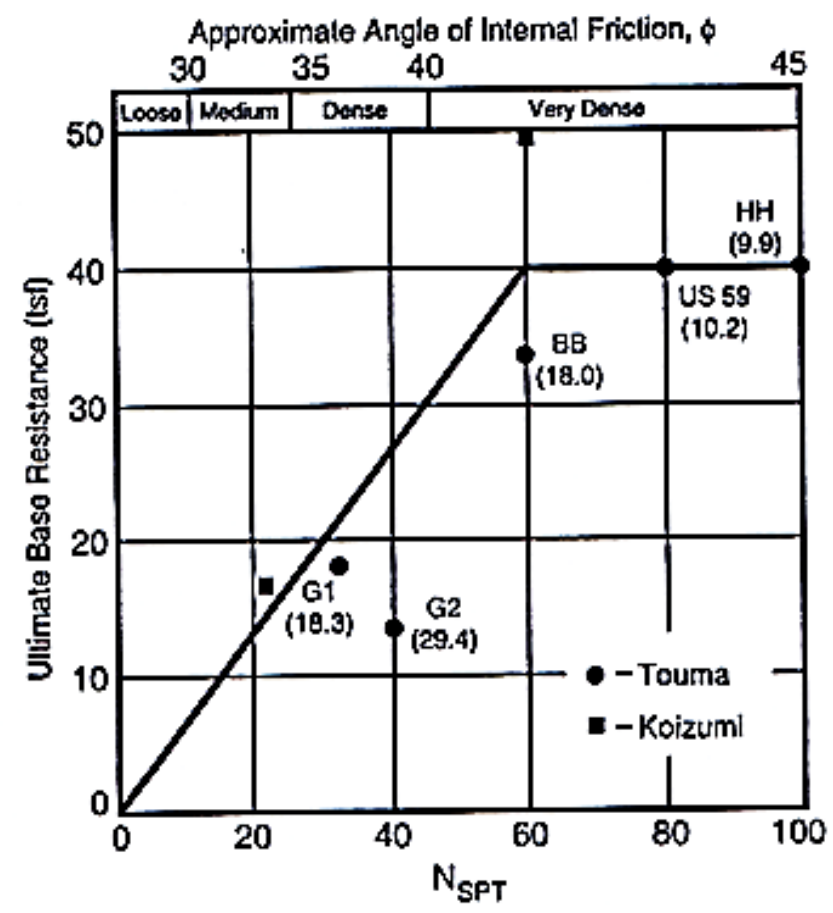

Gambar 1. Nilai tahanan ujung per satuan luas (Sumber: Reese \& Wright 1977)

\section{Analisis daya dukung selimut tiang}

Rumus yang digunakan dalam menghitung daya dukung selimut tiang adalah menggunakan metode Reese \& Wright (1977).

$$
\mathrm{Qs}=\frac{\mathrm{fs} \times \mathrm{L} \times \mathrm{p}}{\mathrm{FK}}
$$

dengan Qs = daya dukung selimut tiang, fs = gesekan selimut tiang, $\mathrm{p}=$ keliling penampang tiang, FK = faktor keamanan.

Pada tanah kohesif, nilai gesekan selimut tiang dapat diperoleh dari faktor adhesi $(\alpha)$ dengan kohesi tanah (cu)

$$
f_{s}=\alpha \cdot c_{u}
$$

dengan $\alpha=$ faktor adhesi, $\mathrm{c}_{\mathrm{u}}=$ kohesi tanah $\left(\operatorname{ton} / \mathrm{m}^{2}\right)$

pada tanah non kohesif, Nilai fs dapat diperoleh dari kolerasi dengan nilai $\mathrm{N}_{\mathrm{spt}}$ seperti pada gambar 2 


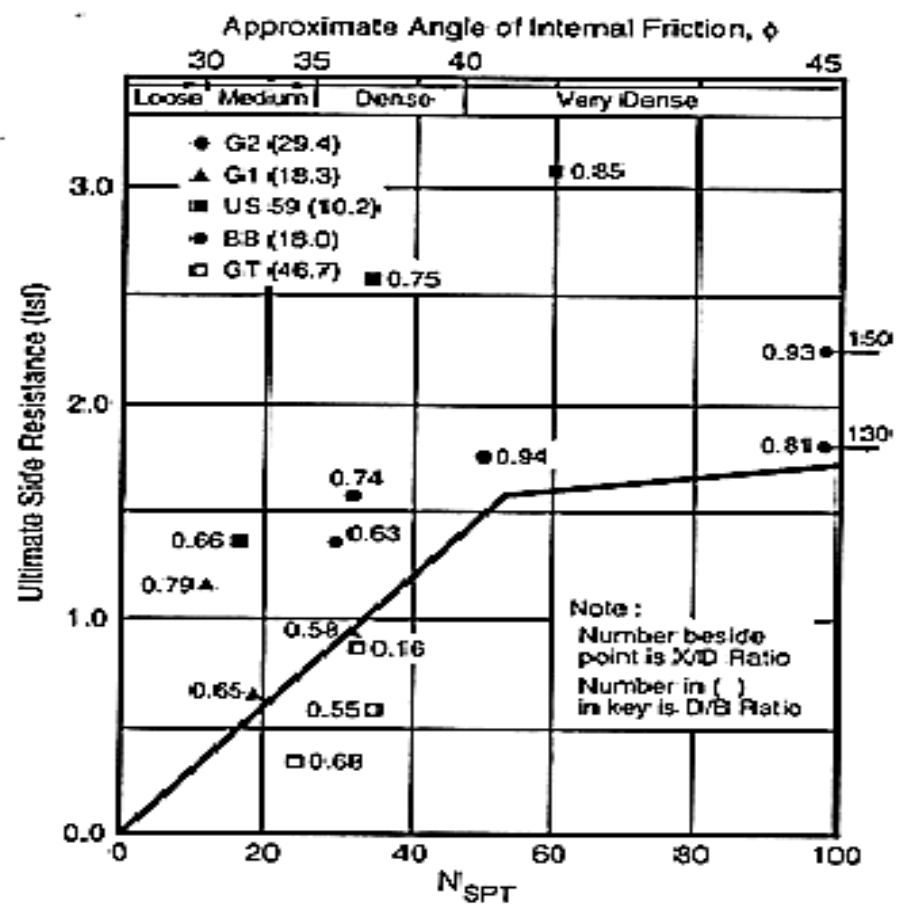

Gambar 2. Hubungan Nspt dengan fs pada tanah non-kohesif (Reese \& Wright, 1977)

\section{Penurunan elastis}

Penurunan fondasi yang terletak pada tanah berbutir halus jenuh dapat dibagi menjadi 3 komponen yaitu: penurunan elastis (immediate settlement), penurunan konsolidasi primer, dan penurunan konsolidasi sekunder. Hardiyatmo (1996). Penurunan elastis dapat dirumuskan sebagai berikut.

$$
S_{e}=\mathrm{q} \times B^{\prime} \times \frac{1-\mu^{2}}{\mathrm{Es}} \times\left(\mathrm{I}_{1} \times \frac{1-2 \mu}{1-\mu} \times \mathrm{I}_{2}\right) \times \text { If }
$$

Dengan $\mathrm{Se}=$ penurunan elastis, $\mathrm{Q}=$ tegangan pada dasar lapisan tanah, $\mathrm{B}^{\prime}=$ ukuran paling minim fondasi, $\mu=$ poisson's ratio, Es = Modulus elastisitas tanah, $\mathrm{I}_{\mathrm{f}}=$ faktor kedalaman.

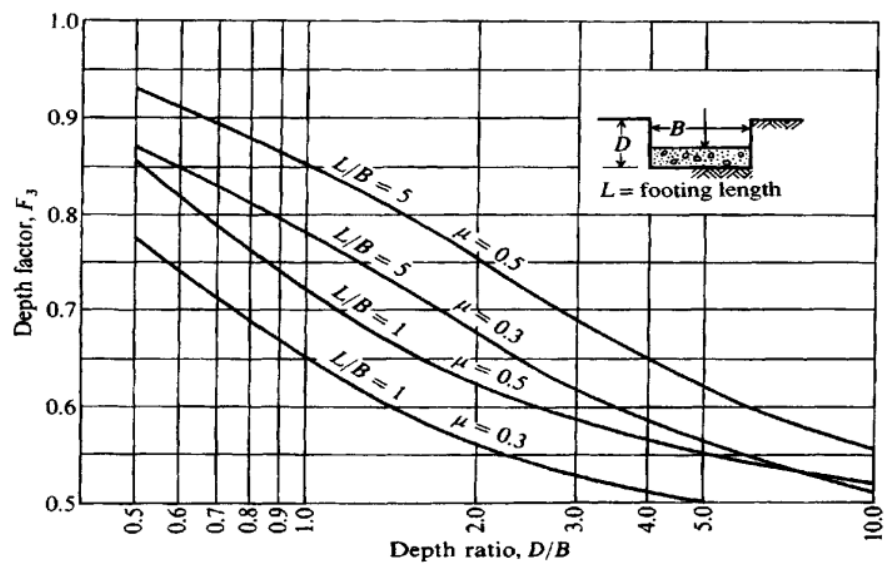

Gambar 3. Grafik faktor $I_{\mathrm{f}}$ (Sumber: Bowles, 1996) 
Tabel 3. Faktor $\mathrm{I}_{1}$ dan $\mathrm{I}_{2}$

\begin{tabular}{lllllllll}
\hline $\mathrm{N}$ & $\mathrm{M}=2.5$ & 4.0 & 5.0 & 6.0 & 7.0 & 8.0 & 9.0 & 10.0 \\
\hline 0.2 & $\mathrm{I}_{1}=0.007$ & 0.006 & 0.006 & 0.006 & 0.006 & 0.006 & 0.006 & 0.006 \\
& $\mathrm{I}_{2}=0.043$ & 0.044 & 0.044 & 0.044 & 0.044 & 0.044 & 0.044 & 0.044 \\
0.4 & 0.026 & 0.024 & 0.024 & 0.024 & 0.024 & 0.024 & 0.024 & 0.024 \\
& 0.074 & 0.075 & 0.075 & 0.075 & 0.075 & 0.075 & 0.075 & 0.075 \\
0.6 & 0.053 & 0.051 & 0.051 & 0.050 & 0.049 & 0.049 & 0.049 & 0.049 \\
& 0.094 & 0.097 & 0.097 & 0.098 & 0.098 & 0.098 & 0.098 & 0.098 \\
0.8 & 0.086 & 0.082 & 0.082 & 0.080 & 0.080 & 0.080 & 0.079 & 0.079 \\
& 0.107 & 0.111 & 0.111 & 0.113 & 0.113 & 0.113 & 0.113 & 0.113 \\
1.0 & 0.121 & 0.115 & 0.115 & 0.112 & 0.112 & 0.112 & 0.111 & 0.111 \\
& 0.114 & 0.120 & 0.120 & 0.123 & 0.124 & 0.124 & 0.124 & 0.124 \\
1.5 & 0.207 & 0.197 & 0.197 & 0.192 & 0.191 & 0.190 & 0.190 & 0.189 \\
& 0.118 & 0.130 & 0.130 & 0.136 & 0.137 & 0.138 & 0.138 & 0.139 \\
2.0 & 0.284 & 0.271 & 0.271 & 0.264 & 0.262 & 0.261 & 0.260 & 0.259 \\
& 0.114 & 0.131 & 0.131 & 0.139 & 0.141 & 0.143 & 0.144 & 0.145 \\
3.0 & 0.402 & 0.392 & 0.392 & 0.378 & 0.378 & 0.376 & 0.374 & 0.373 \\
& 0.097 & 0.122 & 0.122 & 0.122 & 0.141 & 0.144 & 0.145 & 0.147 \\
4.0 & 0.484 & 0.484 & 0.484 & 0.474 & 0.470 & 0.466 & 0.462 & 0.453 \\
& 0.082 & 0.110 & 0.110 & 0.129 & 0.135 & 0.139 & 0.145 & 0.154 \\
5.0 & 0.553 & 0.554 & 0.554 & 0.548 & 0.543 & 0.540 & 0.536 & 0.534 \\
& 0.070 & 0.098 & 0.098 & 0.120 & 0.128 & 0.133 & 0.137 & 0.140 \\
\hline \multirow{2}{*}{3.} & & & & & &
\end{tabular}

(Sumber: Bowles, 1996)

\section{Penurunan konsolidasi primer}

Berikut persamaan-persamaan konsolidasi primer yang digunakan dalam penelitian ini

Untuk konsolidasi normal:

$$
S_{C}=\frac{C_{C} H}{1+e_{o}} \log \left(\frac{p_{o^{\prime}+\Delta p}}{p_{o^{\prime}}}\right)
$$

Untuk konsolidasi berlebih:

$$
S_{C}=\frac{C_{S} H}{1+e_{o}} \log \left(\frac{p_{o^{\prime}+\Delta p}}{p_{o^{\prime}}}\right)
$$

dengan $\mathrm{Sc}=$ penurunan konsolidasi primer, $\mathrm{Cc}=$ indeks kompresi, $\mathrm{Cs}=$ swelling index, $\mathrm{H}=$ tebal lapisan, $\mathrm{e}_{\mathrm{o}}=$ initial void ratio, po' = tegangan effektif, $\Delta p=$ tegangan pada lapisan ketika terbebani.

\section{Penurunan akibat likuifaksi}

Penambahan penurunan yang disebabkan oleh likuifaksi dapat dihitung dari rumus yang diusulkan oleh (Ishii \& Tokimatsu, 1988).

$$
S_{s t}=S_{v} \cdot r_{b}
$$

dengan $S_{\mathrm{st}}=$ total penurunan akibat likuifaksi, $S_{\mathrm{v}}=$ penurunan akibat volumetric strain yang disebabkan oleh gempa, $\mathrm{r}_{\mathrm{b}}=$ faktor akibat deformasi geser. 
Faktor rb dapat diperoleh dari grafik berikut

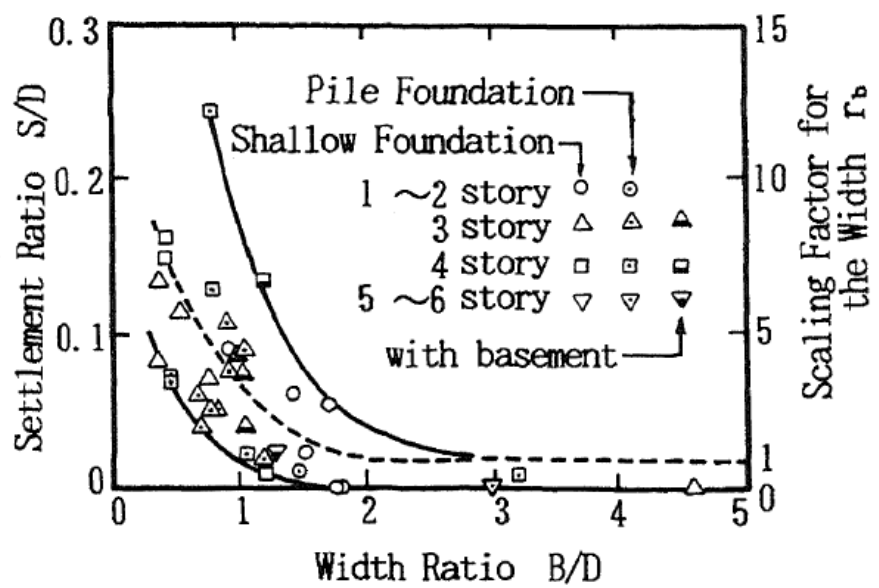

Gambar 4. Hubungan antara settlement ratio dengan width ratio dengan scaling factor $\mathrm{r}_{\mathrm{b}}$

Penurunan akibat volumetric strain dapat dirumuskan oleh (Lee, 2007) sebagai berikut.

$$
\mathrm{S}_{\mathrm{v}}=\sum_{i=1}^{n} H_{i} \varepsilon_{v i}
$$

dengan $\mathrm{H}_{\mathrm{i}}=$ Ketebalan tanah lapisan $\mathrm{i}, \varepsilon_{\mathrm{vi}}=$ nilai volumetric strain lapisan $\mathrm{i}, \mathrm{n}=$ jumlah lapisan tanah.

\section{Data penyelidikan tanah}

Data penyelidikan tanah merupakan hal yang paling penting yang digunakan dalam melakukan penelitian. Pada perhitungan likuifaksi, data SPT dan CPT menunjukan hasil yang hampir sama (Fernando \& Prihatiningsih, 2019). Pada penelitian ini, digunakan data penyelidikan tanah CPT dari GEC (Geotechnical Engineering Consultant) dengan tanah yang berasal dari kota Palu. Data penyelidikan tanah yang digunakan pada penelitian ini ini terdiri 3 data/titik.

\section{Metode rasio tegangan siklik (CSR) dan rasio hambatan siklik (CRR)}

Metode ini digunakan untuk mengetahui potensi likuifaksi. Rumus-rumus CSR dan CRR adalah sebagai berikut.

$$
C S R=0.65 \cdot \frac{a_{\max }}{g} \cdot \frac{\sigma_{v o}}{\sigma^{\prime} v_{0}}
$$

dengan 0.65 = asumsi tegangan geser $65 \%$ seragam, $\mathrm{a}_{\mathrm{max}} / \mathrm{g}=$ percepatan gempa maksimum, $\sigma_{\mathrm{vo}}=$ tegangan beban vertikal, $\sigma^{\prime}{ }_{\text {vo }}=$ tegangan effektif beban vertikal.

$$
C R R=\frac{\tau_{h}}{\sigma_{v}} \cdot \sigma_{v}^{\prime}
$$

dengan $\tau_{h}=$ tegangan geser siklik $\sigma^{\prime}{ }_{v}=$ tegangan effektif beban vertikal.

\section{Metode Tsuchida}

Sebuah metode analisis potensi likuifaksi dengan menggunakan data grainsize distribution. Data ukuran butiran tanah dengan persen butiran yang lolos pada saringan apabila terdapat di bagian dalam kurva, maka tanah tersebut berpotensi likuifaksi. Tetapi apabila data berada di luar kurva, maka tidak berpotensi likuifaksi. 


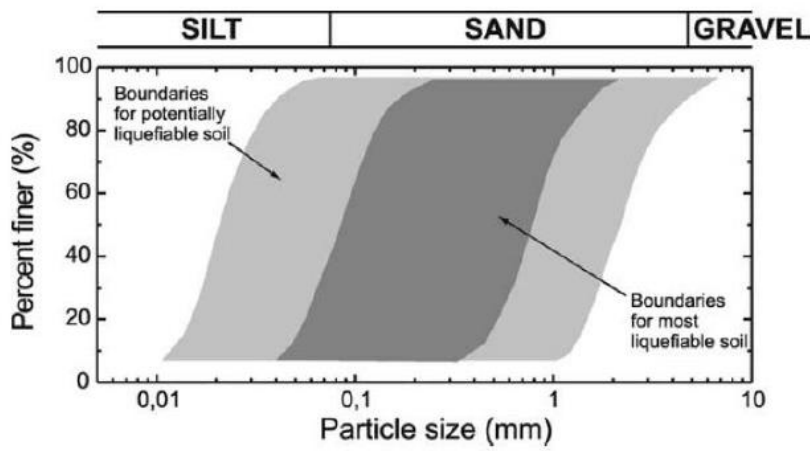

Gambar 5. Grafik hubungan potensi likuifaksi dengan persen kehalusan dan ukuran partikel (Tsuchida, 1970)

\section{Chinese Criteria}

Sebuah metode analisis potensi likuifaksi dengan menggunakan data Liquid Limit (LL) dibandingkan dengan Water Content (Wc). Apabila nilai Liquid Limit kurang dari 35\% dengan Water Content kurang dari 0.9 x Liquid Limit, maka data berpotensi likuifaksi. Jika data terletak pada bagian yang tidak terarsir (test), maka tanah berpotensi likuifaksi.

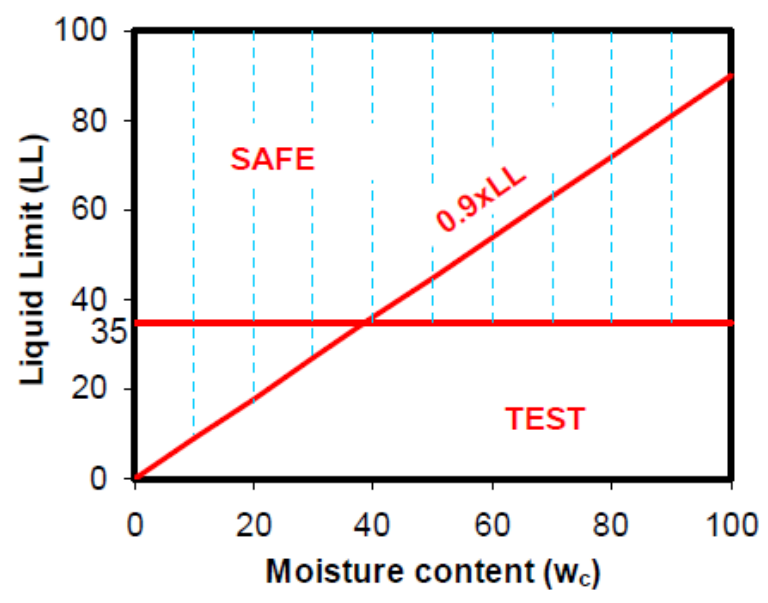

Gambar 6. Grafik chinese criteria (Seed \& Idriss, 1982)

\section{Metode Seed et al}

Metode analisis potensi likuifaksi ini menggunakan data Liquid Limit (LL) dibandingkan dengan Plasticity Index (PI). Apabila nilai Liquid Limit (LL) kurang dari 37\% dan Plasticity Index (PI) kurang dari 12\% maka tanah berpotensi tinggi mengalami likuifaksi. Apabila nilai Liquid Limit (LL) berada diantara 37\%-47\% dan Plasticity Index (PI) berada diantara 12\%-20\% maka tanah berpotensi likuifaksi.

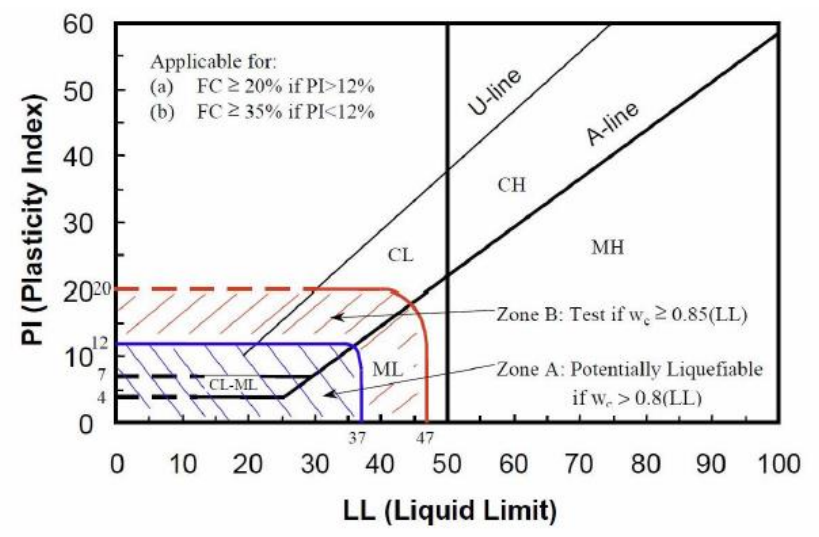


Gambar 7. Grafik metode Seed et al (Seed et al, 1982)

\section{Metode Bray and Sancio}

Metode analisis likuifaksi ini menggunakan perbandingan Water Content dengan Liquid Limit (Wc/LL) dengan Plasticity Index (PI). Jika Wc/LL lebih besar sama dengan dari 0.85 sedangkan PI lebih kecil sama dengan 12 maka tanah perpotensi tinggi likuifaksi. Jika Wc/LL berada diantara 0.8-0,85 sedangkan PI berada diantara $12 \%$ $20 \%$ maka tanah berpotensi mengalami likuifaksi. Jika PI lebih besar dari $20 \%$ maka tanah dianggap terlalu lempung untuk mengalami likuifaksi.

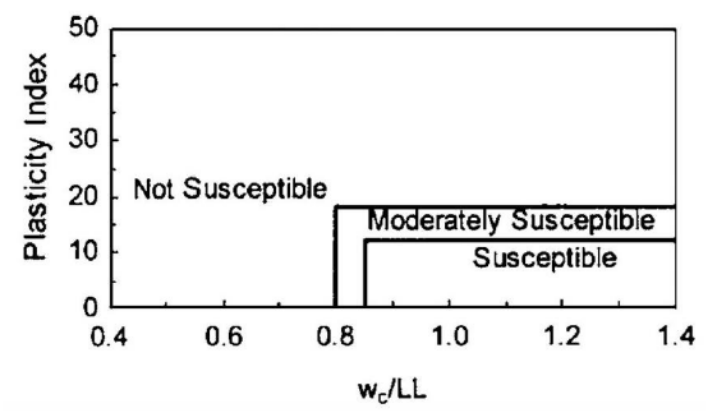

Gambar 8. Grafik hubungan potensi likuifaksi dengan indeks plastisitas dan perbandingan kadar air dengan batas cair (Bray dan Sancio, 2004)

\section{METODE PENELITIAN}

Pada bagian ini akan dijelaskan mengenai tahapan yang digunakan dalam penulisan skripsi ini yang akan dijelaskan melalui gambar diagram alir.

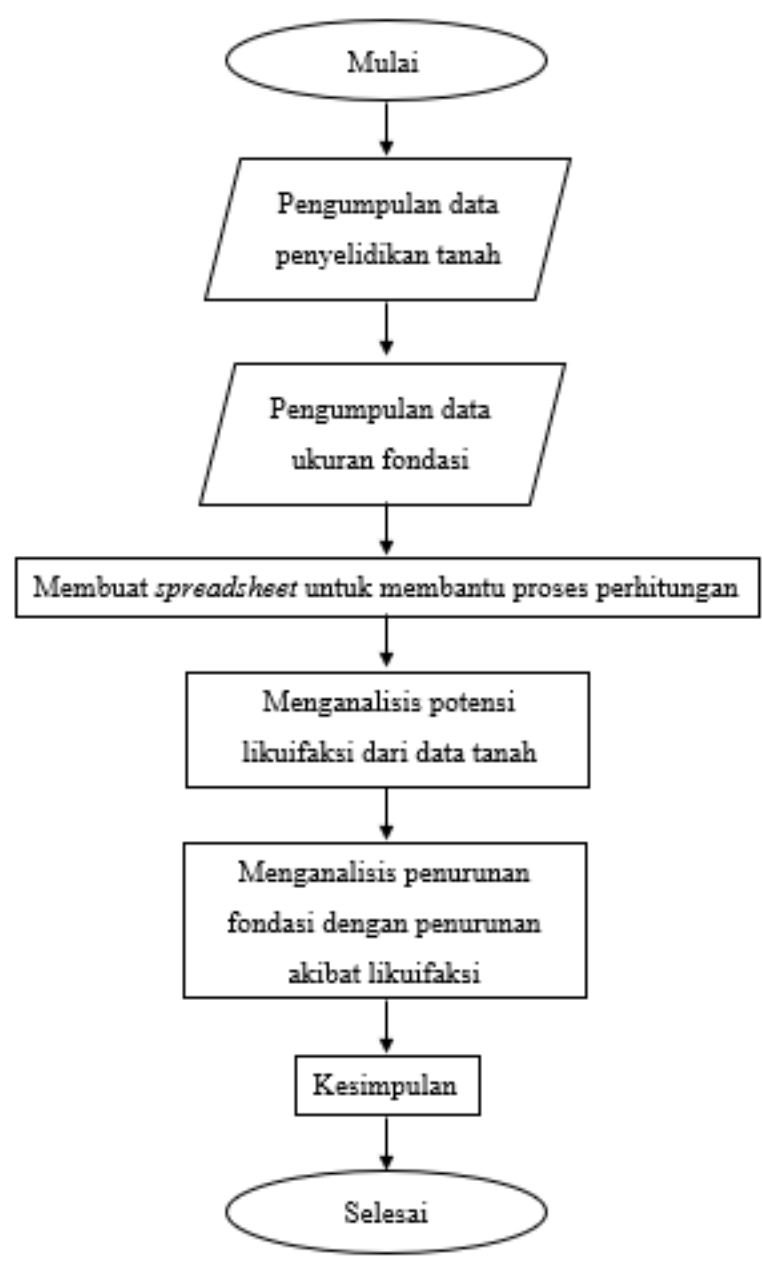


Gambar 9. Diagram alir penelitian

\section{HASIL DAN PEMBAHASAN}

\section{Potensi likuifaksi}

Analisis digunakan 3 sampel pengujian, yaitu CPT 1, CPT 2, dan CPT 3. Untuk penjabaran akan diberikan CPT 1.

\section{Metode Tsuchida}

Hasil analisis metode Tsuchida menunjukan bahwa tanah berpotensi likuifaksi pada setiap kedalaman yaitu, dari kedalaman 0 meter sampai dengan 10.5 meter.

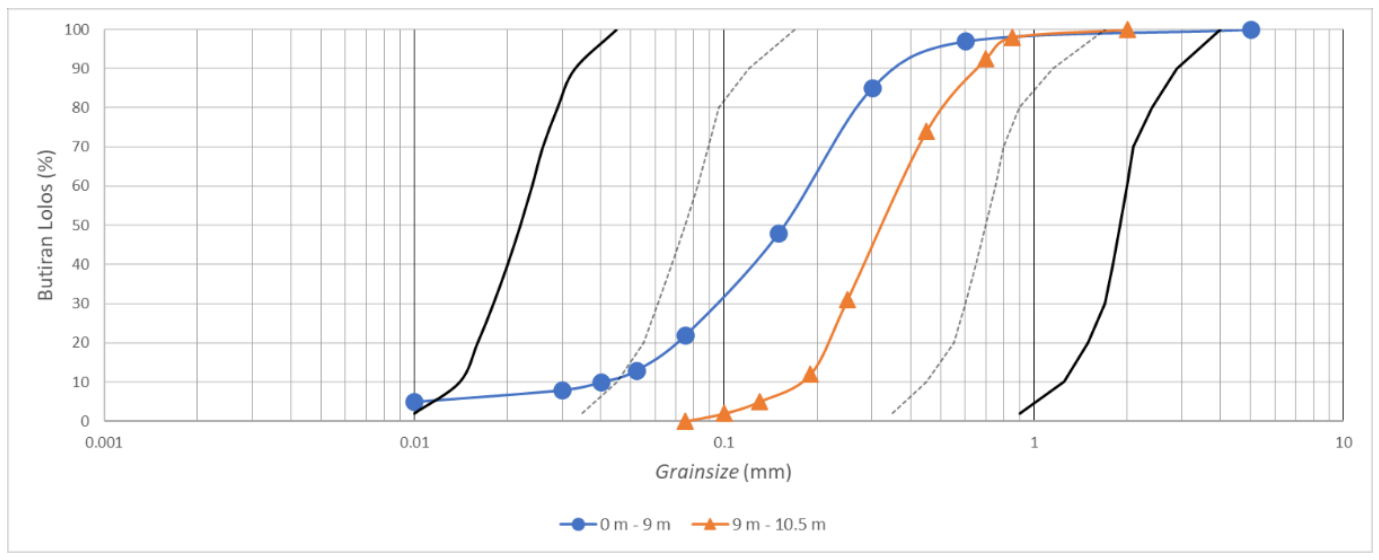

Gambar 10. Hasil metode tsuchida dengan data CPT 1

\section{Metode Chinese Criteria}

Grafik hasil analisis metode Chinese Criteria menunjukan bahwa tanah berpotensi likuifaksi pada setiap kedalaman yaitu, dari kedalaman 0 meter sampai dengan 10.5 meter.

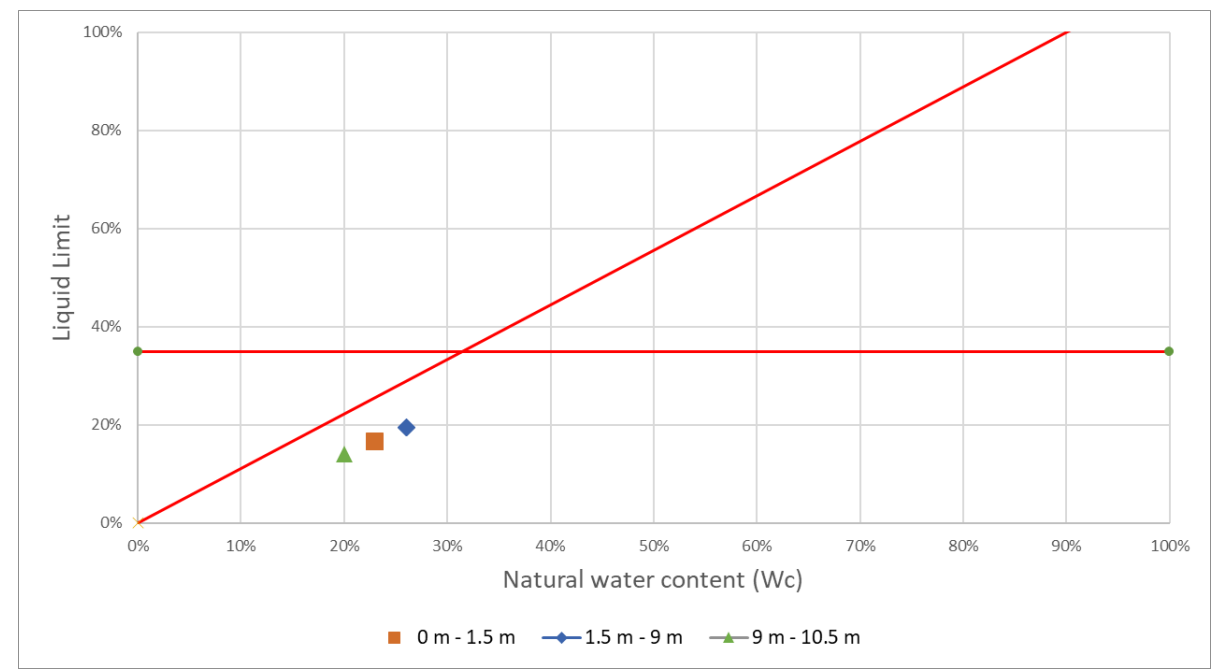

Gambar 11. Hasil metode chinese criteria dengan data CPT 1

\section{Seed et al}

Hasi analisis metode Seed et al menunjukan bahwa pada tanah berpotensi likuifaksi tinggi pada kedalaman 1.5 meter sampai dengan 9 meter, dan berpotensi likuifaksi pada kedalaman 0 meter sampai dengan 1.5 meter dan 9 meter sampai dengan 10.5 meter. 


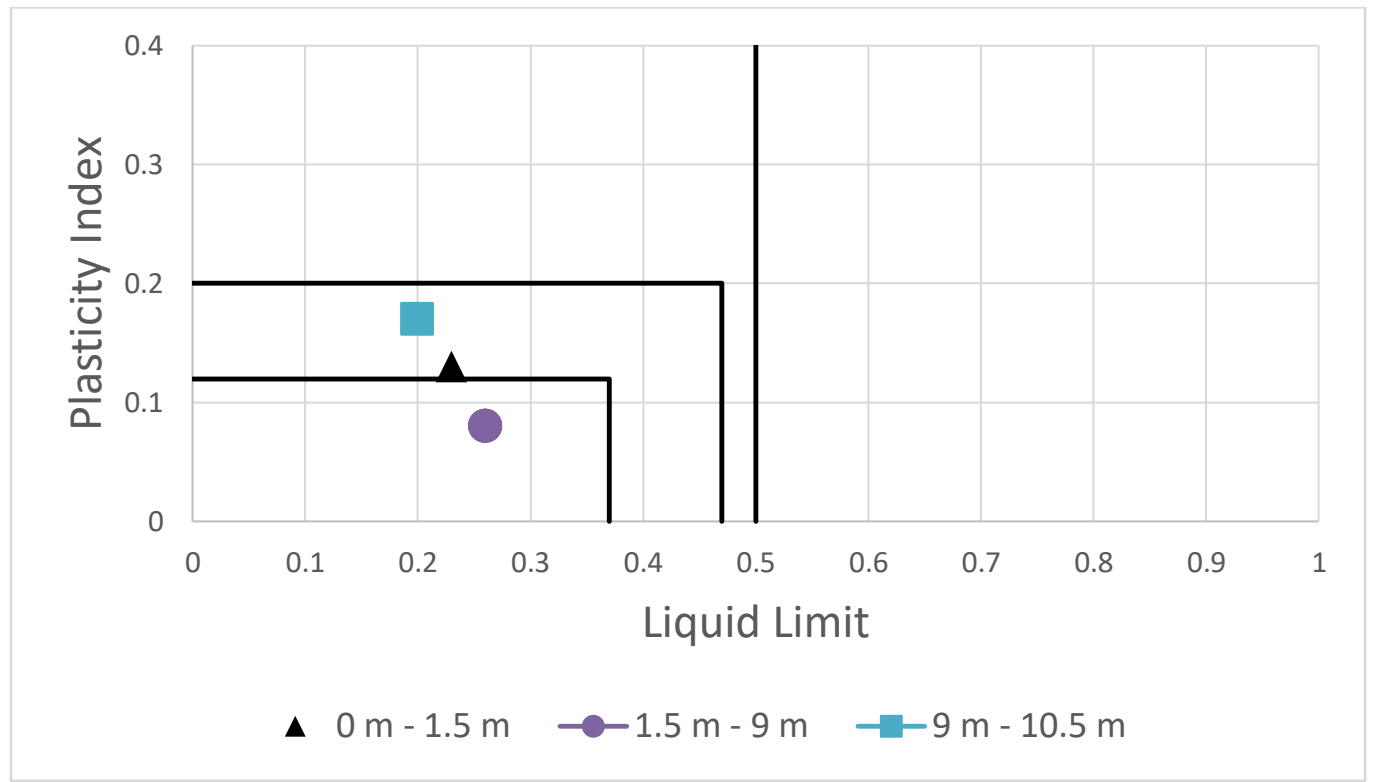

Gambar 12. Hasil metode Seed et al dengan data CPT 1

\section{Bray \& Sancio}

Hasil analisis metode Bray \& Sancio menunjukan bahwa tanah tidak berpotensi likuifaksi pada setiap kedalaman yaitu, dari kedalaman 0 meter sampai dengan 10.5 meter.

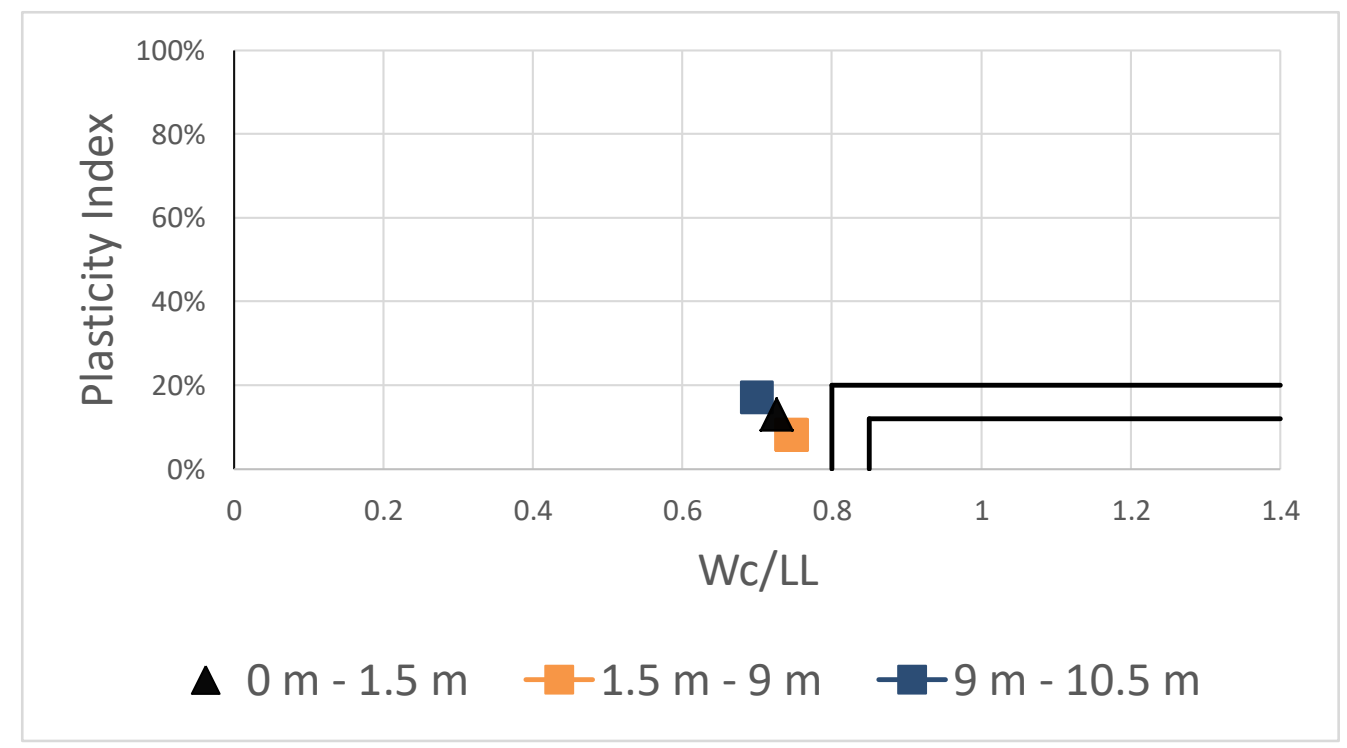

Gambar 13. Hasil metode Bray \& Sancio dengan data CPT 1

\section{Analisis rasio tegangan siklik dan rasio hambatan siklik}

$t_{a v}$ menunjukan bahwa tegangan yang dihasilkan pada tanah ketika gempa terjadi, sedangkan $t_{h}$ menunjukan tegangan yang dapat ditahan oleh tanah sebelum terjadi likuifaksi. Maka Jika nilai $\mathrm{t}_{\mathrm{av}}>\mathrm{t}_{\mathrm{h}}$ maka tanah pada kedalaman tersebut dapat mengalami likuifkasi ketika gempa terjadi. 
Tabel 4. Analisis rasio tegangan siklik (CSR) CPT 1

\begin{tabular}{ccccc}
\hline Kedalaman $(\mathrm{m})$ & $\mathrm{O}_{\mathrm{v}}\left(\mathrm{T} / \mathrm{m}^{2}\right)$ & $\mathrm{a}_{\mathrm{max}} / \mathrm{g}$ & $\mathrm{C}_{\mathrm{D}}(\mathrm{T} / \mathrm{m} 2)$ & $\mathrm{t}_{\mathrm{av}}\left(\mathrm{T} / \mathrm{m}^{2}\right)$ \\
\hline 1,5 & 2,1 & 0,4 & 0,98 & 0,80262 \\
3 & 4,35 & 0,4 & 0,97 & 3,29121 \\
4,5 & 6,6 & 0,4 & 0,96 & 7,41312 \\
6 & 8,85 & 0,4 & 0,95 & 13,1157 \\
7,5 & 11,1 & 0,4 & 0,94 & 20,3463 \\
9 & 13,2 & 0,4 & 0,9 & 27,7992 \\
10,5 & 15,3 & 0,4 & 0,88 & 36,75672 \\
\hline
\end{tabular}

Tabel 5. Analisis rasio hambatan siklik (CRR) CPT 1

\begin{tabular}{cccc}
\hline Kedalaman $(\mathrm{m})$ & $\mathrm{O}_{\mathrm{v}}(\mathrm{T} / \mathrm{m} 2)$ & $\mathrm{t}_{\mathrm{h}} / \mathrm{O}_{\mathrm{v}}{ }^{\prime}$ & $\mathrm{t}_{\mathrm{h}}\left(\mathrm{T} / \mathrm{m}^{2}\right)$ \\
\hline 1,5 & 2,1 & 0,12 & 0,252 \\
3 & 4,35 & 0,06 & 0,261 \\
4,5 & 6,6 & 0,05 & 0,33 \\
6 & 8,85 & 0,03 & 0,2655 \\
7,5 & 11,1 & 0,05 & 0,555 \\
9 & 13,2 & 0,045 & 0,594 \\
10,5 & 15,3 & 0,085 & 1,3005 \\
\hline
\end{tabular}

Jika nilai $\mathrm{t}_{\mathrm{av}}>\mathrm{t}_{\mathrm{h}}$ maka tanah pada kedalaman tersebut berpotensi mengalami likuifaksi

Tabel 6. Rangkuman analisis CSR dan CRR

\begin{tabular}{ccccrrrrrr}
\hline \multirow{2}{*}{ Kedalaman $(\mathrm{m})$} & \multicolumn{3}{c}{$\mathrm{t}_{\mathrm{av}}\left(\mathrm{T} / \mathrm{m}^{2}\right)$} & \multicolumn{3}{c}{$\mathrm{t}_{\mathrm{h}}\left(\mathrm{T} / \mathrm{m}^{2}\right)$} & \multicolumn{3}{c}{ Kesimpulan } \\
\cline { 2 - 9 } & $\mathrm{C}-1$ & $\mathrm{C}-2$ & $\mathrm{C}-3$ & \multicolumn{1}{c}{$\mathrm{C}-1$} & \multicolumn{1}{c}{$\mathrm{C}-2$} & $\mathrm{C}-3$ & $\mathrm{C}-1$ & $\mathrm{C}-2$ & $\mathrm{C}-3$ \\
\hline $0-1,5$ & 0,8026 & 1,2842 & 1,46765 & 0,252 & 0,792 & 0,792 & YES & YES & YES \\
$1,5-3,0$ & 3,2912 & 4,9368 & 5,44752 & 0,261 & 0,1125 & 0,216 & YES & YES & YES \\
$3,0-4,5$ & 7,4131 & 10,873 & 11,3668 & 0,33 & 0,396 & 0,69 & YES & YES & YES \\
$4,5-6,0$ & 13,116 & 19,018 & 19,3401 & 0,2655 & 0,3915 & 0,45 & YES & YES & YES \\
$6,0-7,5$ & 20,346 & 29,299 & & 0,555 & 0,486 & & YES & YES & \\
$7,5-9,0$ & 27,799 & 39,382 & & 0,594 & 0,2423 & & YES & YES & \\
$9,0-10,5$ & 36,757 & & & 1,3005 & & & YES & & \\
\hline
\end{tabular}

Hasil analisis menunjukan bahwa tanah dapat mengalami likuifaksi pada kedalaman 0 meter sampai dengan 10.5 meter.

\section{Asumsi berat bangunan}

Perhitungan berat bangunan diperoleh dari berat jenis beton dikali dengan volume total bangunan 


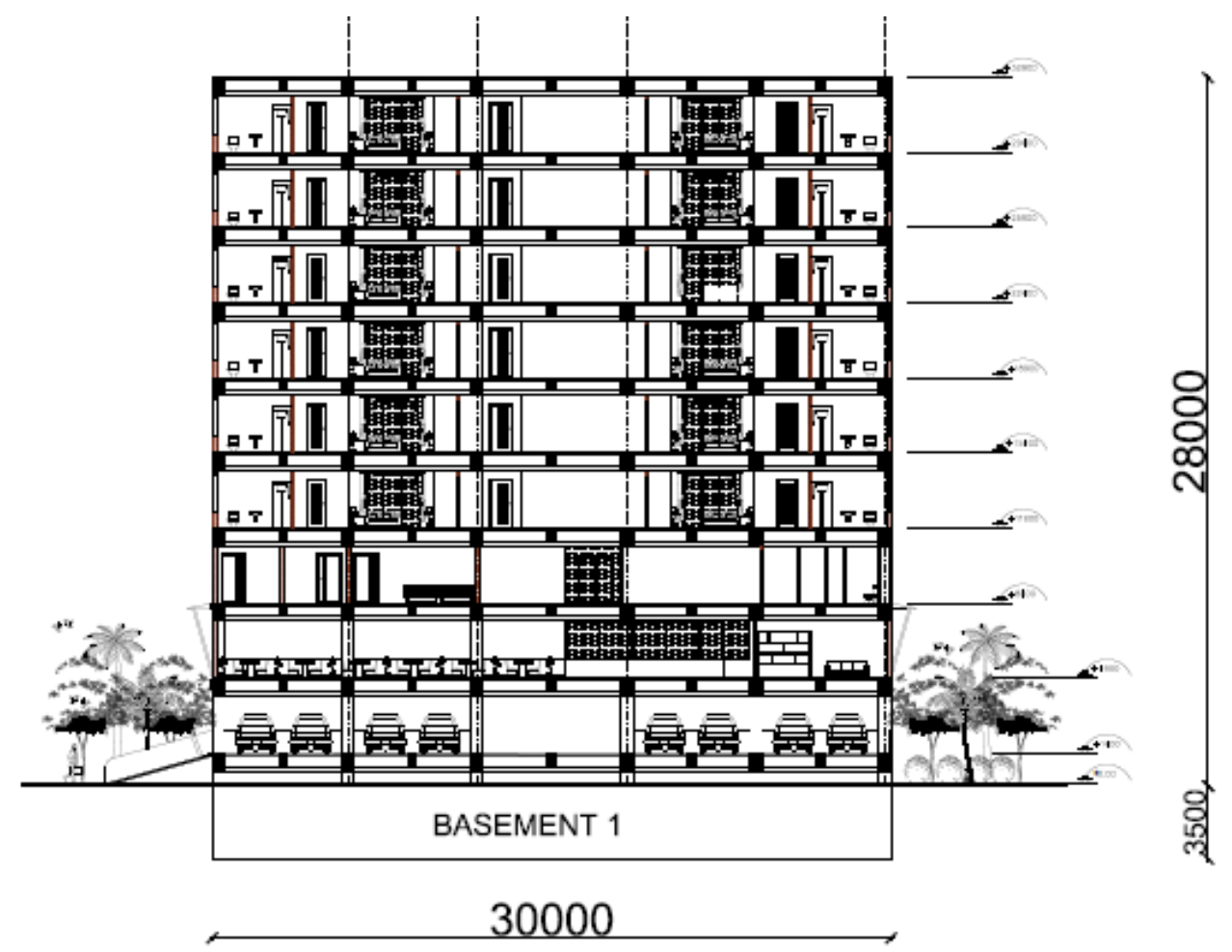

Gambar 14. Bentuk bangunan dengan 1 basement yang akan dihitung

Pada penelitian ini berat bangunan diperoleh dari volume bangunan yang akan dihitung lalu dikalikan dengan berat jenis beton yang ditampilkan pada tabel 4 .

Tabel 7. Asumsi berat bangunan

\begin{tabular}{ll}
\hline Jenis beban & Berat $(\mathrm{kN})$ \\
\hline Berat bangunan & 90720 \\
Berat basement & 30240 \\
Berat bangunan + basement & 120960
\end{tabular}

Berat jenis beton yang digunakan $=24 \mathrm{kN} / \mathrm{m} 2$

\section{Daya dukung fondasi rakit}

Nilai daya dukung fondasi rakit menggunakan rumus 1 diperoleh nilai daya dukung fondasi rakit pada kedalaman 10.5 meter sebesar $2437.3 \mathrm{kN} / \mathrm{m}^{2}$.

\section{Daya dukung fondasi tiang}

Dari hasil analisis menggunakan rumus yang diusulkan oleh Reese \& Wright (1977) diperoleh daya dukung tiang sebagai berikut.

Tabel 8. Daya dukung fondasi tiang

\begin{tabular}{|c|c|c|}
\hline \multirow{3}{*}{ Kedalaman $10.5 \mathrm{~m}$} & \multicolumn{2}{|c|}{ Daya Dukung $(\mathrm{kN})$} \\
\hline & Sebelum likuifkasi & saat Likuifaksi \\
\hline & 295 & 127,23 \\
\hline
\end{tabular}




\section{Distribusi beban}

Distribusi beban dalam penelitian ini dibagi menjadi 2 kombinasi berdasarkan pada SNI 8460:2017. Kombinasi pertama adalah $75 \%$ beban diterima fondasi rakit $25 \%$ diterima oleh fondasi tiang, dan kombinasi ke- 2 adalah $25 \%$ beban diterima fondasi rakit dan $75 \%$ diterima oleh fondasi tiang.

\section{Jumlah tiang}

Dari hasil analisis dari daya dukung tiang, semakin panjang tiang pada umumnya semakin besar kapasitas daya dukung tiangnya. Semakin besar kapasitas tiang maka, jumlah tiang yang dibutuhkan dalam perencanaan akan semakin sedikit. Jumlah tiang diperoleh dari besar beban yang diterima oleh tiang dibagi dengan kapasitas daya dukung tiang. Jarak antar tiang tidak melebihi 2.5 dari diameter tiang.

Tabel 9. Jumlah tiang kombinasi 1 sebelum likuifaksi

\begin{tabular}{cccccc}
\hline \multirow{2}{*}{$\begin{array}{c}\text { Pile } \\
\text { Length } \\
(\mathrm{m})\end{array}$} & Total Piles & \multicolumn{5}{c}{ Pile Location } \\
\cline { 3 - 6 } & $\mathrm{X} 1$ & $\mathrm{X} 2$ & $\mathrm{X}$ & $\mathrm{Y}$ \\
\hline 7,50 & 448,00 & 48,33 & $-0,33$ & 49,00 & 10,00 \\
8,50 & 187,00 & 42,19 & 5,81 & 43,00 & 5,00 \\
\hline
\end{tabular}

Tabel 10. Jumlah tiang kombinasi 2 sebelum likuifaksi

\begin{tabular}{cccccc}
\hline \multirow{2}{*}{$\begin{array}{c}\text { Pile } \\
\text { Length }(\mathrm{m})\end{array}$} & Total Piles & \multicolumn{5}{c}{ Pile Location } \\
\cline { 3 - 6 } & & $\mathrm{X} 1$ & $\mathrm{X} 2$ & $\mathrm{X}$ & $\mathrm{Y}$ \\
\hline 8,50 & 458,00 & 48,54 & $-0,54$ & 49,00 & 10,00 \\
\hline
\end{tabular}

Tabel 11. Jumlah tiang setelah likuifaksi

\begin{tabular}{|c|c|c|c|c|c|}
\hline \multirow{2}{*}{$\begin{array}{c}\text { Pile } \\
\text { Length } \\
\text { (m) }\end{array}$} & \multirow{2}{*}{ Total Piles } & \multicolumn{4}{|c|}{ Pile Location } \\
\hline & & $\mathrm{X} 1$ & $\mathrm{X} 2$ & $X$ & $\mathrm{Y}$ \\
\hline 8,50 & 544,00 & 50,23 & $-2,23$ & 51,00 & 11,00 \\
\hline
\end{tabular}

\section{Penurunan}

Penurunan pada fondasi tiang rakit dapat dilihat pada tabel 12, 13 dan 14.

Tabel 12. Penurunan total fondasi tiang rakit sebelum likuifaksi

\begin{tabular}{ccc} 
& Tepi fondasi $(\mathrm{mm})$ & Tengah fondasi $(\mathrm{mm})$ \\
\cline { 2 - 3 } Kombinasi 1 & 271.76 & 338.58 \\
Kombinasi 2 & 287.48 & 359.41 \\
\hline
\end{tabular}


Tabel 13. Penurunan fondasi akibat likuifaksi

\begin{tabular}{cccccc}
\hline Kedalaman $(\mathrm{m})$ & $\left(\mathrm{N}_{1}\right)_{60}$ & $\begin{array}{c}\text { Volumetric Strain } \\
(\%)\end{array}$ & $\begin{array}{c}\mathrm{S}_{\mathrm{V}} \\
(\mathrm{mm})\end{array}$ & $\mathrm{r}_{\mathrm{b}}$ & $\begin{array}{c}\mathrm{S}_{\mathrm{ST}} \\
(\mathrm{mm})\end{array}$ \\
\hline $0-1,5$ & 16 & 2 & 30 & 4 & 120 \\
$1,5-3$ & 7 & 3 & 45 & 4 & 180 \\
$3-4,5$ & 5 & 4 & 60 & 4 & 240 \\
$4,5-6$ & 5 & 4 & 60 & 4 & 240 \\
$6-7,5$ & 6 & 3,2 & 48 & 4 & 192 \\
$7,5-9$ & 4 & 4 & 60 & 4 & 240 \\
$9-10,5$ & 9 & 2,5 & 37,5 & 4 & 150 \\
$10,5-12$ & 35 & 1 & 15 & 4 & 60 \\
\hline
\end{tabular}

Total penambahan penurunan fondasi akibat likuifaksi yaitu, $1422 \mathrm{~mm}$.

Tabel 14. Penurunan total fondasi tiang rakit sesudah likuifaksi

\begin{tabular}{ccc}
\hline & Tepi fondasi $(\mathrm{mm})$ & Tengah fondasi $(\mathrm{mm})$ \\
\cline { 2 - 3 } kombinasi 1 & 1693,76 & 1760,58 \\
kombinasi 2 & 1709,48 & 1781,41 \\
\hline
\end{tabular}

\section{KESIMPULAN DAN SARAN}

\section{Kesimpulan}

Berdasarkan hasil analisis dan perhitungan, ada beberapa hal yang dapat disimpulkan. Kesimpulan diperoleh sebagai berikut.

1. Hasil analisis potensi likuifaksi secara umum menunjukan bahwa tanah diselidiki di Sulawesi terindikasi mengalami likuifaksi. Hal ini dapat dilihat pada gambar 4.4 sampai dengan 4.15. Hasil analisis menggunakan metode Chinese Criteria menunjukan likuifaksi terjadi pada kedalaman lebih dari 3 meter. Hasil analisis metode Tsuchida menggungkapkan bahwa masih ada bagian yang dapat mengalami likuifaksi. Khusus metode Bray and Sancio potensi likuifaksi tidak terjadi pada setiap kedalaman. Untuk metode Seed et al likuifaksi masih terjadi di bawah kedalaman lebih dari 3 meter. Untuk hasil analisis CSR (Cyclic Stress Ratio) dan CRR (Cyclic Resistance Ratio) disimpulkan bahwa likuifaksi terjadi pada setiap kedalaman.

2. Tiang mengalami penurunan daya dukung yang cukup signifikan ketika likuifaksi terjadi (daya dukung selimut tiang diabaikan). Daya dukung tiang pada kedalaman 12 meter berubah dari $159.98 \mathrm{kN}$ menjadi $69.98 \mathrm{kN}$.

3. Jumlah tiang yang dibutuhkan pada fondasi tiang rakit bertambah cukup signifikan ketika likuifkasi terjadi. Jumlah tiang yang dibutuhkan berubah dari 187 buah menjadi 544 buah tiang.

4. Kontribusi penurunan tanah yang disebabkan oleh likuifaksi sangat signifikan, penurunan tanah total saat likuifaksi terjadi yaitu $1422 \mathrm{~mm}$.

5. Penurunan fondasi tiang rakit secara keseluruhan telah melebihi penurunan yang diizinkan pada SNI 8460-2017 yaitu sudah melebihi $15 \mathrm{~cm}$.

\section{Saran}

Berdasarkan hasil analisis ada beberapa saran sebagai berikut.

1. Untuk pehitungan penurunan sebaiknya dihitung secara 3 dimensi agar lebih akurat.

2. Data-data tes tanah harus diperbanyak agar data tanah tidak perlu lagi dikolerasi sehingga diperoleh datadata sesuai dengan kondisi tanah yang sebenarnya.

3. Titik-titik pengetesan tanah harus diperbanyak agar dapat mengetahui kondisi tanah di lapangandalam gambaran yang besar. 


\section{DAFTAR PUSTAKA}

Badan Standardisasi Nasional. SNI 8460-2017 Persyaratan Perancangan Geoteknik. Jakarta, 2017.

Bowles. Foundation Analysis And Design. Illinois: The McGraw-Hill Companies, 1996.

Bray, J D, et al. "Liquefaction Susceptibility of Fine-grained Soils." Journal of Geotechnical and Geoenvironmental Engineering (2004).

Fernando, Nicky and Aniek Prihatiningsih. "Analisis Potensi Cyclic Mobility pada Tanah Kohesif." (2019).

Ishii, Yusuke and Kohji Tokimatsu. "Simplified Procedure For the Evaluation of Settlement of Structures During Earthquake." Proceedings of Ninth World Conference on Earthquake Engineering (1988): 99-100.

Poulos, H G and E H Davis. Pile Foundation Analysis and Design. Canada: Rainbow Bridge Book, 1980.

Reese, Lymon C and Stephen J Wright. Drilled Shaft Manual. Washington: U.S. Dept. of Transportation Federal Highway Administration, 1977.

Seed, Bolton and Idriss. Ground Motion and Soil Liquefaction During Earthquake. Berkeley: Earthquake Engineer Research Institute, 1982.

Tsuchida, H. "Prediction and Countermeasure against Liquefaction in Sand Deposits." Abstract of the Seminar of the Port and Harbour Research Institute (1970).

Terzaghi, K. Theoretical Soil Mechanics. Wiley, 1943. 
